\title{
Posterior fossa tumors in children with neurofibromatosis type 1 (NF1)
}

\author{
Ignacio Pascual-Castroviejo
}

Received: 7 September 2010 /Accepted: 9 September 2010/Published online: 24 September 2010

(C) Springer-Verlag 2010

\section{Dear Editor,}

Thanks to our friend Prof. J.F. Martínez Lage for his letter indicating that in our paper on "Posterior fossa tumors in children with neurofibromatosis type 1 (NF1)", we did not include his report on a case of medulloblastoma associated with NF1 published in 2002 and another case published by Robles Cascallar in 1992. We offer him and his colleagues, as well as to
Dr. Robles Cascallar, our apologies for the unintentional omissions. We had searched PubMed prior to publication of our paper for all reported cases of NF1 associated with medulloblastoma and vice versa, but did not find the references to either paper. Obviously, we are very pleased to know about the existence of both these papers, as well as for the opportunity to correct the failure to include these in our references.

I. Pascual-Castroviejo $(\bowtie)$

Pediatric Neurology, University Hospital La Paz,

Madrid, Spain

e-mail: i.pcastroviejo@neurologia.e.telefonica.net 